\title{
Surfactant Phospholipid Metabolism in 3-Day and 3-Day Postmature Rabbits In Vivo
}

\author{
ALAN JOBE ${ }^{(39)}$ \\ Fetal-Maternal Research Laboratories, Los Angeles County Harbor-UCLA Medical Center, Torrance, \\ California, USA
}

\section{Summary}

Three-day-old normal and 3-day postmature rabbits (prepared by human chorionic gonadotropin treatment of the does) were given injections of the radiolabeled phospholipid precursors palmitic acid, choline, and glycerol. The specific activities as cpm/ $\mu \mathrm{mol}$ phospholipid phosphate were measured for phosphatidylcholine, disaturated phosphatidylcholine, phosphatidylglycerol, phosphatidylinositol, and phosphatidylethanolamine from lung and alveolar wash fraction lipid extracts of 3-day-old rabbits. Specific activities similarly were measured for phosphatidylcholine and disaturated phosphatidylcholine from postmature rabbits. Curves describing the appearance of labeled phospholipids into the alveolar wash fraction demonstrated that in both 3-day and postmature rabbits, phospholipid secretion was delayed for 3 to $4 \mathrm{hr}$. Thereafter, there was a rapid accumulation of labeled phospholipids until 12 to $16 \mathrm{hr}$ after labeled precursor injection. The curves were similar for all measured phospholipids and all labeled precursors studied. The phospholipid compositions of lung and alveolar wash fraction lipid extracts were determined by analysis of the various phospholipids separated by two-dimensional thin-layer chromatography. Forty percent of lung samples and 35\% of alveolar wash samples from postmature rabbits contained no detectable phosphatidylglycerol, whereas all 22 lung and surfactant samples from 3-day-old rabbits contained this phospholipid.

\section{Speculation}

The appearance of phosphatidylglycerol in amniotic fluid is thought to signal lung maturity in the human fetus. The present work in the 3-day-old rabbit shows that the strikingly slow kinetics of labeling of surfactant phospholipids in newborn rabbits (24) does not "mature" to adult rabbit (21) labeling patterns synchronously with the appearance of phosphatidylglycerol. Rather, alveolar wash phospholipid composition "matures" without major changes in the kinetics of labeling of the alveolar wash phospholipids. Relative to adult rabbits, the delay of 3 to $4 \mathrm{hr}$ in the appearance of labeled phospholipids in the alveolar wash characteristic of the perinatal rabbit may reflect different processing of phospholipids from synthesis through packaging and storage in lamellar bodies to secretion.

The observation that lungs from premature infants who died of the respiratory distress syndrome contained less surface active material than did the lungs of infants dying from other causes (2) led to extensive developmental studies of lung phospholipid metabolism using animal models $(5,11,12,32,36)$. Such studies have resulted in clinical tests to predict lung maturity in utero $(9,10)$, in methods to "induce" lung maturation in utero with corticosteroids $(27,33)$, and in improved therapy for infants with the respiratory distress syndrome $(13,34)$. Recent studies in rats (19), lambs (1), and rabbits (30) suggest that surfactant replacement therapy may be applicable to the human; however, the basic difference between lung surfactant metabolism between perinatal and adult mammals remain controversial (31). Radiolabeled phospholipid precursors have been used to study subcellular synthesis, storage, and secretion of phosphatidylcholine in fetal (26), premature (23), term newborn $(14,24)$, and adult rabbits $(21,25)$. These studies are consistent with the anatomic descriptions of the subcellular metabolism of surfactant $(7,8)$, and they have shown striking differences between perinatal and adult rabbits in the kinetics of labeled phosphatidylcholine secretion to the alveolar space.

The composition of the amniotic fluid phospholipids changes as the human lung approaches maturity. Specifically, high relative amounts of phosphatidylinositol in the amniotic fluid of the fetus (18) or tracheal aspirate (16) of an infant with respiratory distress syndrome indicates a maturing lung. The presence of phosphatidylglycerol in amniotic fluid assures that the respiratory distress syndrome will not occur $(6,18)$, and infants with the respiratory distress syndrome do not have phosphatidylglycerol in tracheal aspirates until the disease has resolved (16). Similar changes in surfactant phospholipid composition with development were documented in the rabbit; however, phosphatidylglycerol was not detected in the rabbit until after birth (17).

We have reported previously that lung phospholipid metabolism is similar in fetal, term, and premature newborns and very different from that in adult rabbits (21-26). Three-day-old and three-day postmature rabbits were studied here to identify changes in phospholipid metabolism during extrauterine development. Radiolabeled phospholipid precursors were used to measure the kinetics of secretion of labeled phosphatidylcholine, disaturated phosphatidylcholine, phosphatidylglycerol, phosphatidylinositol, and phosphatidylethanolamine.

\section{MATERIALS AND METHODS}

\section{ANIMALS}

Forty-four 3-day-old New Zealand White rabbits were taken from the nest approximately $4 \mathrm{hr}$ before study. The animals were given injections of the appropriate isotope solution over 3 to $5 \mathrm{sec}$ via the external jugular vein (22). The rabbits were kept warm and fed by gavage with $2 \mathrm{ml}$ of SMA infant formula (Wyeth Laboratories) every $6 \mathrm{hr}$ as before (22-24). All of the rabbits appeared healthy throughout the experiment.

Pregnant rabbits at 26 days gestational age, bred simultaneously with those who delivered at term, were given injections of 200 units of human chorionic gonadotropin to inhibit spontaneous labor and to cause postmaturity as described by Shapiro and Roux (37). At 3 days postterm ( 34 days gestational age), at the same time that the 3 -day-old rabbits were studied, the postmature pregnant rabbits were given injections via an ear vein with $2 \mathrm{mCi}$ $\left[{ }^{3} \mathrm{H}\right]$ palmitic acid and sacrificed $10 \mathrm{~min}$ later with a rapid IV dose of $600 \mathrm{mg}$ pentobarbital (Euthanol). The postmature fetal rabbits were rapidly delivered, dried, and kept warm in a heated box (23). This protocol was identical to that used previously for premature (23) and term newborn rabbits (24). Approximately $1 \mathrm{hr}$ after delivery, they were given injections of the appropriate isotopic 
solution via the external jugular vein. The rabbits were anesthetized with IP pentobarbital and killed by severing the aorta to allow exanguination (24)

\section{LUNG AND ALVEOLAR WASH ISOLATION}

After killing, the chest of each rabbit was opened, and the trachea was cannulated. The airways were washed repeatedly with $0.9 \% \mathrm{NaCl}(11,24)$. The washes were pooled and extracted to give a lipid extract of the alveolar wash fraction. Each lung was stripped of major bronchi and blood vessels and homogenized in $5 \mathrm{ml}$ saline (24). An aliquot of the homogenate was extracted to yield a lipid extract of lung tissue.

\section{ISOTOPES}

$\left[1-{ }^{14} \mathrm{C}\right]$ Palmitic acid $(50.2 \mathrm{mCi} / \mathrm{mmole}),\left[9,10-{ }^{3} \mathrm{H}\right]$ palmitic acid (23.5 $\mathrm{Ci} / \mathrm{mmole})$, [methyl ${ }^{3} \mathrm{H}$ ]choline chloride $(4.2 \mathrm{Ci} / \mathrm{mmole})$, and [2- $\left.{ }^{3} \mathrm{H}\right]$ glycerol $(6.48 \mathrm{Ci} / \mathrm{mmole})$ were purchased from New England Nuclear. The palmitic acid isotopes were stabilized in a $4 \%$ bovine serum albumin solution $(21,24)$ and diluted appropriately with saline for injection, as were the other isotopes.

\section{PHOSPHOLIPID ANALYSIS}

Lipid extracts of lung and surfactant fractions were obtained by the method of Bligh and Dyer (4), and all samples were concentrated under $\mathrm{N}_{2}$ at $50^{\circ} \mathrm{C}$. Phosphatidylcholine was isolated from each sample by two-dimensional, thin-layer chromatography on hand made Silica Gel $\mathrm{H}$ plates, and the phosphatidylcholine was recovered by filtration with Teflon Millipore filters (21). Disaturated phosphatidylcholine was isolated from lipid extracts following treatment with $\mathrm{OsO}_{4}$ as described by Mason et al. (29). In addition, the product from the alumina columns was further purified by chromatography of the disaturated phosphatidylcholine on Silica Gel $\mathrm{H}$ plates (22). Following methylation and gas chromatography, the fatty acid composition of the disaturated phosphatidylcholine was $89 \%$ palmitic acid, $6 \%$ myristic acid, and $5 \%$ stearic acid (22).

Aliquots of purified phosphatidylcholine and disaturated phosphatidylcholine solutions were used to measure phospholipid phosphate according to Bartlett (3) as well as radioactivity in Aquasol scintillation fluid (New England Nuclear) (21, 24). Specific activities were determined for each sample as $\mathrm{cpm} / \mu \mathrm{mol}$ phospholipid phosphate.

The other lung and alveolar wash phospholipids were isolated from the lipid extracts on two plates, each loaded with the same amount of extract. The plates were developed together in two dimensions, and the phospholipids were visualized with iodine vapor and identified (25). The phospholipid spots from one plate were wet with water and scraped into scintillation vials for deter- minations of radioactivity. The phospholipid spots from the other plate were similarly scraped for phosphate analysis (3). Specific activities for each phospholipid were calculated as $\mathrm{cpm} / \mu \mathrm{mol}$ phospholipid phosphate.

The phospholipid compositions of the lung and alveolar wash lipid extracts were determined following two-dimensional, thinlayer chromatography as above. Each phospholipid spot was scraped for phosphate assay, and a composition was calculated (25). A phospholipid spot could be consistently detected if it represented greater than 0.3 to $0.4 \%$ of the total phospholipids on a plate.

\section{RESULTS}

\section{ANIMAL MODEL}

The 3-day-old rabbits had a mean weight of $67.2 \pm 1.89 \mathrm{~g}$ $( \pm$ S.E.; $N=44$ ). The compositions of the phospholipids isolated from lung and alveolar wash fractions from these 3-day-old rabbits are given in Table 1.

The 3-day postmature animals from 6 litters weighed $61.3 \pm$ $1.97 \mathrm{~g}$ (mean \pm S.E.; $N=49$ ), a mean value not very different from that of the 3-day-old animals. These postmature rabbits had the same teeth, hair, and nail characteristics as did the 3-day-old rabbits and soon after birth were indistinguishable from the normal animals. However, at birth, a number of the animals developed respiratory distress as evidenced by cyanosis and tachypnea; this resolved over several hr. Because all the animals were not distressed at birth, these postmature rabbits probably represent a heterogenous group. An additional 8 pregnant rabbits were treated with human chorionic gonadotropin, and all pregnancies went postterm. Either all or the majority of the animals in these litters had died in utero, apparently shortly before delivery.

The relative amounts of all major phospholipid species except phosphatidylinositol were significantly different in postmature than in 3-day-old rabbits. The lung tissue of the postmature animals contained about $10 \%$ more phosphatidylcholine relative to the other lung phospholipids than did the lung tissue of 3-dayold rabbits. The mean value for lung phosphatidylglycerol was less than one-half that measured for the 3-day-old rabbits. The amount of phosphatidylglycerol detected in lung extracts from individual rabbits indicated that $40 \%$ had no detectable phosphatidylglycerol (Table 2).

The overall phospholipid composition of the alveolar wash fractions of the 3-day and 3-day postmature rabbits were similar, however, significant differences in phosphatidylglycerol, phosphatidylinositol, and sphingomyelin content were detected (Table 1). Again many of the postmature rabbits had no phosphatidylglycerol detected in the alveolar wash (Table 2).

The technique of IV injection of labeled phospholipid precur-

Table 1. Percentage of phospholipid composition of lung and alveolar wash fractions

\begin{tabular}{|c|c|c|c|c|c|c|}
\hline \multirow[b]{2}{*}{ Phospholipid ( $N$ ) } & \multicolumn{3}{|c|}{ Lung tissue } & \multicolumn{3}{|c|}{ Alveolar wash } \\
\hline & 3 day olds (22) & $\begin{array}{l}3 \text { day postmature } \\
\text { (15) }\end{array}$ & $P^{1}$ & 3 day olds (22) & $\begin{array}{l}3 \text { day postmature } \\
(23)\end{array}$ & $\boldsymbol{P}$ \\
\hline Phosphatidylcholine & $49.74 \pm 0.61^{2}$ & $60.80 \pm 0.87$ & $<0.001$ & $79.24 \pm 0.52$ & $79.08 \pm 0.77$ & NS \\
\hline Phosphatidylethanolamine & $18.02 \pm 0.44$ & $15.62 \pm 0.49$ & $<0.01$ & $4.74 \pm 0.18$ & $4.21 \pm 0.27$ & NS \\
\hline Phosphatidylserine & $6.38 \pm 0.30$ & $2.57 \pm 0.24$ & $<0.001$ & tr & tr & \\
\hline Phosphatidylglycerol & $2.08 \pm 0.17$ & $0.81 \pm 0.20$ & $<0.001$ & $4.20 \pm 0.31$ & $1.69 \pm 0.38$ & $<0.001$ \\
\hline Phosphatidylinositol & $3.87 \pm 0.17$ & $3.67 \pm 0.23$ & $\mathbf{N S}^{3}$ & $7.46 \pm 0.35$ & $8.66 \pm 0.48$ & $<0.01$ \\
\hline Unknown phospholipid & $6.36 \pm 0.36$ & $3.90 \pm 0.24$ & $<0.001$ & tr & tr & \\
\hline Sphingomyelin & $12.64 \pm 0.27$ & $11.10 \pm 0.46$ & $<0.05$ & $1.15 \pm 0.09$ & $3.67 \pm 0.42$ & $<0.01$ \\
\hline Lysophosphatidylcholine & $\mathrm{tr}^{4}$ & $\operatorname{tr}^{4}$ & & $1.65 \pm 0.50$ & $1.13 \pm 0.40$ & NS \\
\hline Lysobiphosphatidic acid & $1.14 \pm 0.11$ & $0.97 \pm 0.16$ & NS & $1.72 \pm 0.15$ & $1.83 \pm 0.26$ & NS \\
\hline
\end{tabular}

${ }^{1} P$ values were determined using the $t$ statistic for unpaired observations, corrected for the number of $t$ tests performed for the lung tissue and alveolar wash phospholipids (20).

${ }^{2}$ All measurements \pm S.E.

${ }^{3} \mathrm{NS}$ is $P>0.05$.

4 tr equals less than $0.5 \%$. 
Table 2. Phosphatidylglycerol in 3-day and 3-day postmature rabbits ${ }^{1}$

\begin{tabular}{lccc}
\hline & \multicolumn{3}{c}{ Lung } \\
\cline { 2 - 4 } & No. PG $^{2}$ & $<1 \%$ PG & $>1 \%$ PG \\
\hline 3-day olds (22) & $0^{4}$ & 2 & 20 \\
3-day postmatures (15) & 6 & 2 & 7 \\
\hline \multicolumn{3}{c}{ Alveolar wash } \\
\hline 3-day olds (22) & No. PG & $<2 \%$ PG & $>2 \%$ PG \\
\cline { 2 - 4 } 3-day postmatures (23) & 0 & 1 & 21 \\
\hline
\end{tabular}

'A $\chi^{2}$ analysis of the distribution of the number of animals among the three categories of PG content indicated a significant difference $(P<0.01)$ for the PG content in 3-day versus 3-day postmature rabbits in both lung and alveolar wash fractions.

${ }^{2}$ PG, phosphatidylglycerol.

${ }^{3}$ Numbers in parentheses, number of animals studied.

${ }^{4}$ Number of animals.

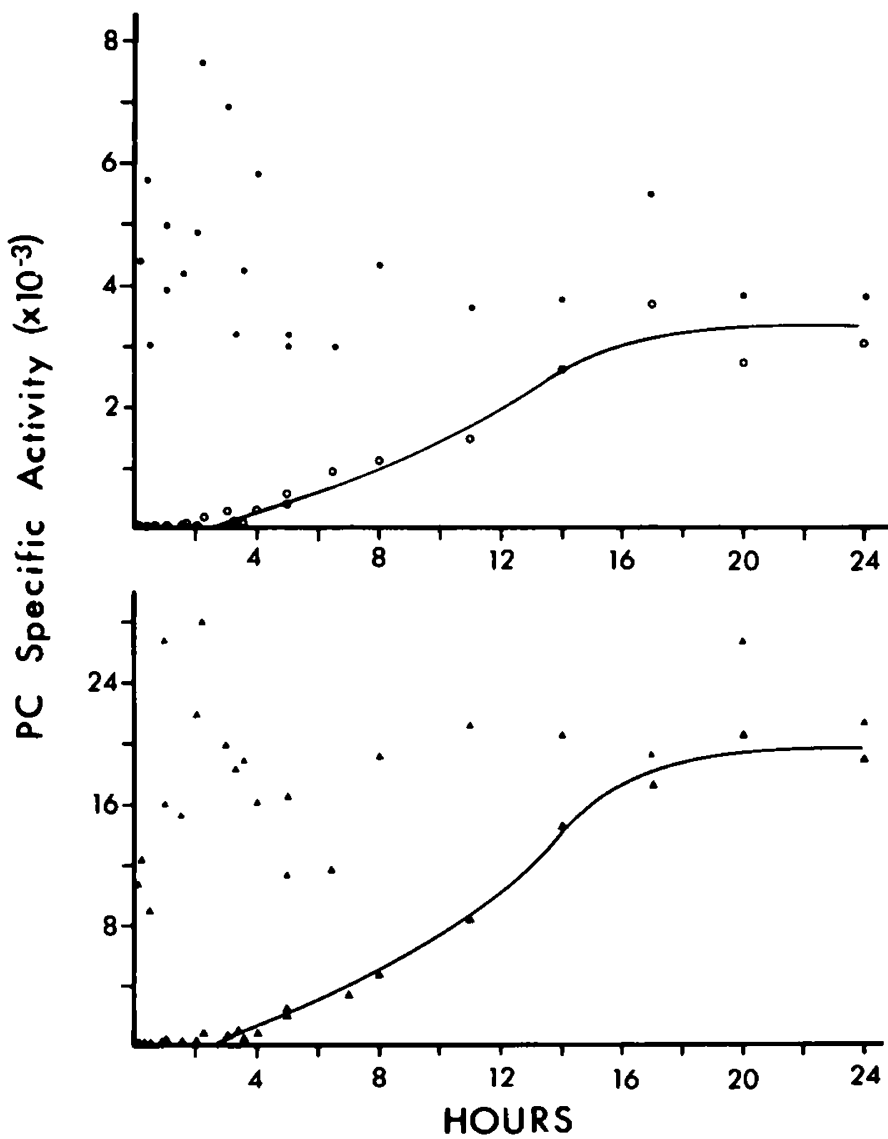

Fig. 1. Labeling of alveolar wash phosphatidylcholine in 3-day-old rabbits. Twenty-one 3-day-old rabbits were given injections via the external jugular vein simultaneously with $0.5 \mu \mathrm{Ci}\left[{ }^{14} \mathrm{C}\right]$ plamitic acid and $1 \mu \mathrm{Ci}$ $\left.{ }^{3} \mathrm{H}\right]$ choline per $10 \mathrm{~g}$ body weight. Phosphatidylcholine was isolated from the lipid extracts of the lung and alveolar wash fractions. The specific activity was measured as counts $/ \mathrm{min} / \mu \mathrm{mol}$ phosphatidylcholine phosphate. Specific activity was plotted against time in $\mathrm{hr}$. 0 , lung phosphatidylcholine labeled with $\left[{ }^{14} \mathrm{C}\right]$ palmitic acid; $O$, alveolar wash phosphatidylcholine labeled with $\left[{ }^{14} \mathrm{C}\right]$ palmitic acid; $\Delta$, lung phosphatidylcholine labeled with $\left[{ }^{3} \mathrm{H}\right]$ choline; $\Delta$, alveolar wash phosphatidylcholine labeled with $\left[{ }^{3} \mathrm{H}\right]$ choline.

sors was selected to pulse label the lung phospholipids. The IV dose adjusted to animal weight did not give equal labeling of the lung phospholipids between animals. The specific activities of lung phosphatidylcholine labeled with $\left[{ }^{14} \mathrm{C}\right]$ palmitic acid varied widely for the 12 animals sacrificed within $4 \mathrm{hr}$ of isotope administration, at times before decay should perturb the measurements appreciably (Fig. 1). The mean specific activity of phosphatidylcholine labeled with $\left[{ }^{14} \mathrm{C}\right]$ palmitic acid was $4991 \pm 430 \mathrm{cpm} / \mu \mathrm{mol}$ phosphate $( \pm S . E$.). Because this variability probably represented either a variable dosage of the isotope reaching the lung due to pulmonary blood flow or variable concentrations of the endogenous unlabeled precursors present either in the blood or the lung itself, the specific activity values measured in the alveolar wash fraction from a given animal should be corrected for the amount of isotope initially incorporated into the phospholipid of interest in the lung tissue. However, that value was not known because decay of the labeled phospholipids from the lung may have occurred. Although decay of isotope from lung phosphatidylcholine is very slow in term newborn rabbits (24), that might not be true for 3-day-old rabbits or for phospholipids other than phosphatidylcholine.

The alveolar wash phospholipid-specific activities could be corrected for this animal variability by first using the lung-specific activity data to calculate a decay curve. The ratio of each experimental value to the value calculated from the derived decay curve could then be used as a correction factor for the differences in labeling between animals. This sort of correction was used in Figs. 2 to 4 . If no decay were present, a simple ratio of the specific activity of the alveolar wash phospholipid to the corresponding specific activity of the lung phospholipid similarly would correct for the amount of isotope an animal initially incorporated. This convention was used for Figures 5 and 6 because there were insufficient numbers of animals within any experiment to calculate decay curves.

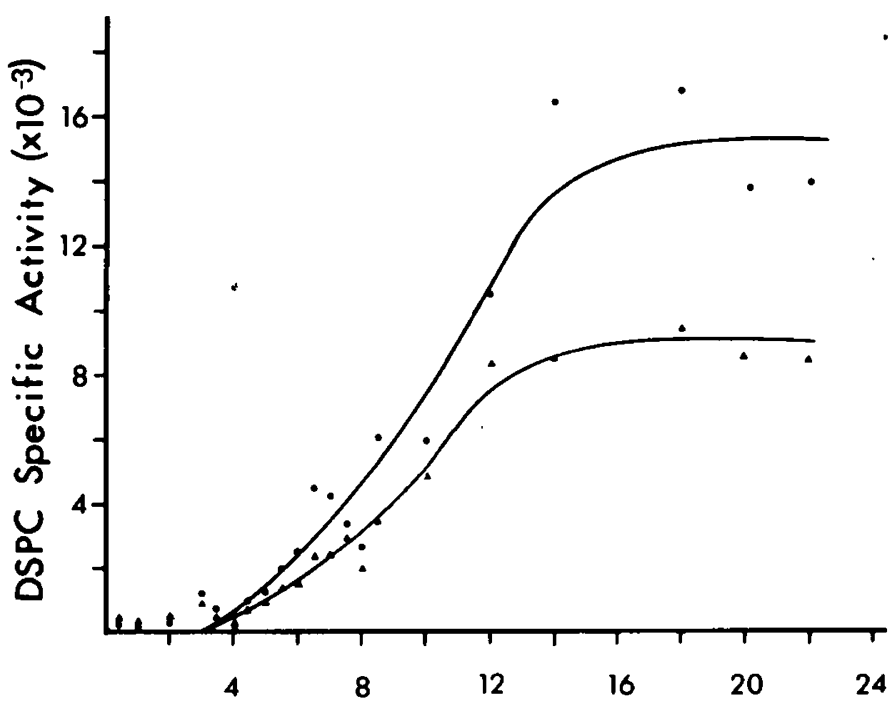

HOURS

Fig. 2. Labeling of alveolar wash disaturated phosphatidylcholine in 3-day-old rabbits. Twenty-one rabbits were given injections simultaneously with $32 \mu \mathrm{Ci}\left[{ }^{3} \mathrm{H}\right.$ ]glycerol and $2 \mu \mathrm{Ci}\left[{ }^{14} \mathrm{C}\right.$ ]palmitic acid per $10 \mathrm{~g}$ body weight. At times up to $22 \mathrm{hr}$, the animals were killed, and lipid extracts of the lung and alveolar wash fractions were used for the isolation of disaturated phosphatidylcholine. A specific activity of disaturated phosphatidylcholine from each lung and alveolar wash fraction was determined as $\mathrm{cpm} / \mu \mathrm{mol}$ disaturated phosphatidylcholine phosphate. The specific activity values from the alveolar wash samples were corrected for animal variability by first calculating a decay curve from the lung disaturated phosphatidylcholine specific activity data. Very little decay was apparent as the respective values from the curves for the ${ }^{14} \mathrm{C}$ and ${ }^{3} \mathrm{H}$ labels were $t_{1 / 2}=90 \mathrm{hr}(r=0.144)$, and $t_{1 / 2}=49 \mathrm{hr}(r=0.237)$. alveolar wash fraction disaturated phosphatidylcholine labeled with $\left[{ }^{14} \mathrm{C}\right]$ palmitic acid; $\Delta$, alveolar wash fraction disaturated phosphatidylcholine labeled with $\left[{ }^{3} \mathrm{H}\right]$ glycerol. 


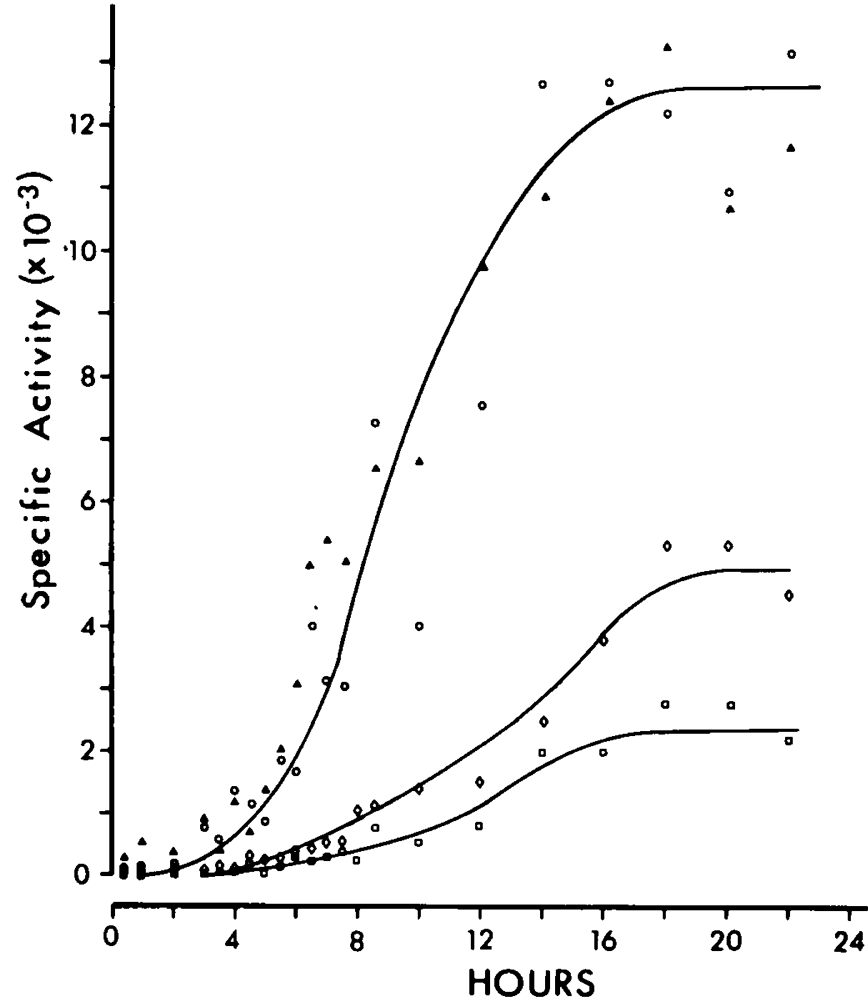

Fig. 3. Labeling of alveolar wash phospholipids with $\left[{ }^{14} \mathrm{C}\right]$ palmitic acid. Lipid extracts from the lung and alveolar wash fractions of the same animals described in Figure 2 were used to determine the specific activities of four different lung and alveolar wash phospholipids in the $\mathbf{4 2}$ samples from 21 animals. The specific activities of the phospholipids isolated from the lung were used to calculate decay curves, and each alveolar wash phospholipid specific activity was corrected for animal variability (see "Results" and Fig. 2). $O$, phosphatidylcholine; $\Delta$, phosphatidylglycerol; $\diamond$, phosphatidylinositol; $\square$, phosphatidylethanolamine.

\section{LABELING OF ALVEOLAR WASH PHOSPHATIDYLCHOLINE IN 3-DAY-OLD RABBITS}

The specific activities of lung and alveolar wash phosphatidylcholine labeled with $\left[{ }^{14} \mathrm{C}\right]$ palmitic acid and $\left[{ }^{3} \mathrm{H}\right]$ choline are shown in Figure 1. The overall shape of the secretion curve for the accumulation of labeled phosphatidylcholine in the alveolar wash fraction was apparent from the data uncorrected for animal variability. Very little labeled phosphatidylcholine was detected in the alveolar wash fraction until 3 to $4 \mathrm{hr}$ after isotope injection. Label then accumulated in a reasonably linear fashion until maximal specific activity was achieved. The curve was similar in shape using either $\left[{ }^{14} \mathrm{C}\right]$ palmitic acid or $\left[{ }^{3} \mathrm{H}\right]$ choline as labeled phospholipid precursors.

\section{LABELING OF ALVEOLAR WASH DISATURATED} PHOSPHATIDYLCHOLINE IN 3-DAY-OLD RABBITS

Rabbits were given injections simultaneously with $\left[{ }^{3} \mathrm{H}\right]$ glycerol and $\left[{ }^{14} \mathrm{C}\right]$ palmitic acid. The appearance of labeled disaturated phosphatidylcholine into the alveolar wash fraction was then measured over a period of $22 \mathrm{hr}$ (Fig. 2). As with phosphatidylcholine, the labeled disaturated phosphatidylcholine was not detected in the alveolar wash until 3 to $4 \mathrm{hr}$ after isotope injection, and following relatively linear accumulation, maximal specific activity was detected by about 12 to $16 \mathrm{hr}$. The secretion curves were very similar using either $\left[{ }^{14} \mathrm{C}\right]$ palmitic acid or $\left[{ }^{3} \mathrm{H}\right]$ glycerol as labels of disaturated phosphatidylcholine.

\section{LABELING OF OTHER ALVEOLAR WASH PHOSPHOLIPIDS}

Palmitic acid and glycerol were selected as general precursors for the study of the labeling of phospholipids other than phopha- tidylcholine and disaturated phosphatidylcholine. Following incorporation by the lung, the accumulation of labeled phospholipids in the alveolar wash fraction was measured over a 22-hr period (Figs. 3 and 4). The specific activity curves for phosphatidylcholine and phosphatidylglycerol labeled with $\left[{ }^{14} \mathrm{C}\right]$ palmitic acid were superimposable (Fig. 3), again with little labeled phospholipid detected within 3 to $4 \mathrm{hr}$ after isotope injection. Rapid accumulation occurred between 4 and 12 to $16 \mathrm{hr}$. The labeled phosphatidylinositol and phosphatidylethanolamine appeared in the alveolar wash fraction at much lower specific activities, consistent with the observation that less isotope is incorporated into these phospholipids (25). The curves generated using the $\left[{ }^{3} \mathrm{H}\right]$ glycerol label had a similar shape (Fig. 4) to those determined with the palmitate label (Fig. 3).

\section{LABELING OF ALVEOLAR WASH PHOSPHATIDYLCHOLINE AND DISATURATED PHOSPHATIDYLCHOLINE IN 3-DAY POSTMATURE RABBITS}

By giving pregnant postterm rabbits injections with $\left[{ }^{3} \mathrm{H}\right]$ palmitic acid $10 \mathrm{~min}$ before delivery and $\left[{ }^{14} \mathrm{C}\right]$ palmitic acid or $\left[{ }^{14} \mathrm{C}\right]$ choline approximately $1 \mathrm{hr}$ after delivery of the animals, lung phosphatidylcholine labeled before and at delivery by the fetuses and by the newborns after birth could be studied in the same animals. Although labeling of lung phosphatidylcholine within a litter following the maternal dose of isotope was reasonably uniform, the mean specific activities between litters varied considerably. Furthermore, the specific activity of the phosphatidylcholine labeled by injection of the newborns varied similarly to that measured for the 3 day olds. Because the postmature rabbits were studied for a maximum of $14 \mathrm{hr}$, the specific activities of the alveolar wash fraction phosphatidylcholine and disaturated phosphatidylcholine were expressed as ratios to the specific activities of their respective lung phospholipids. The curves for the specific activities for alveolar wash phosphatidylcholine and disaturated phosphatidylcholine labeled at birth and $1 \mathrm{hr}$ after birth were

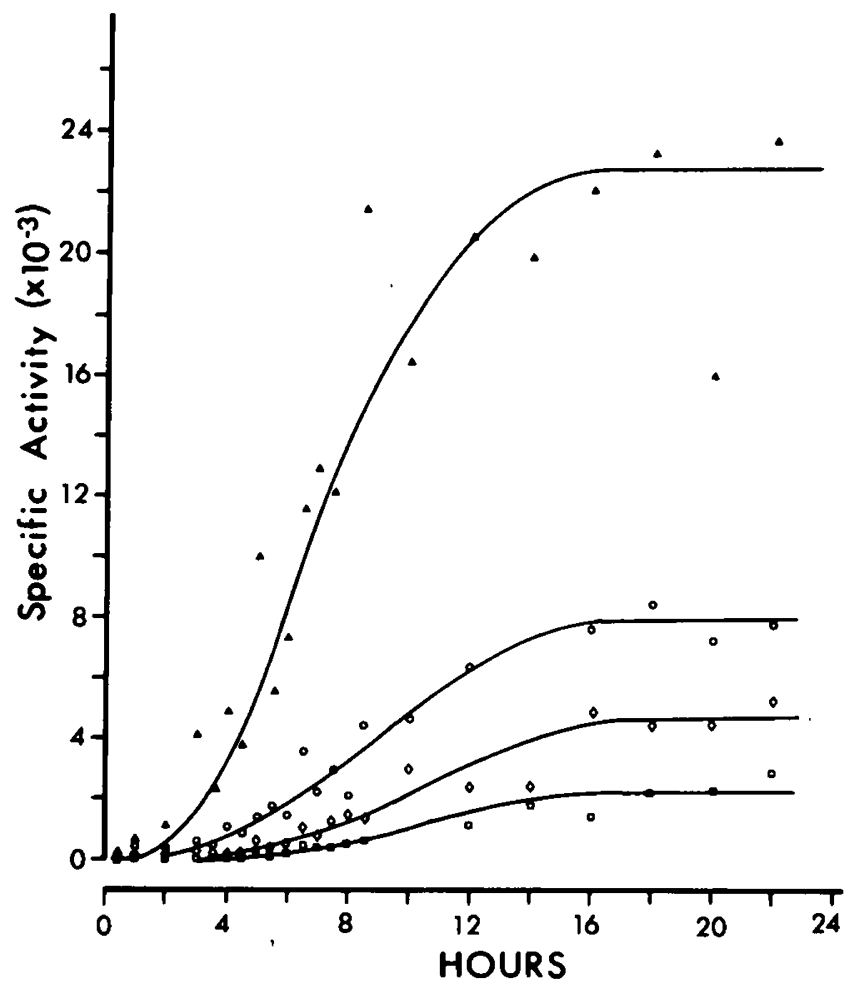

Fig. 4. Labeling of alveolar wash phospholipids with $\left[{ }^{3} \mathrm{H}\right]$ glycerol. Lipid extracts from the animals described in Figures 2 and 3 were used for measuring the specific activities of lung and alveolar wash fraction phospholipids. The data are presented as in Figure 3. $O$, phosphatidylcholine; $\Delta$, phosphatidylglycerol; $\diamond$, phosphatidylinositol; $\square$, phosphatidylethanolamine. 


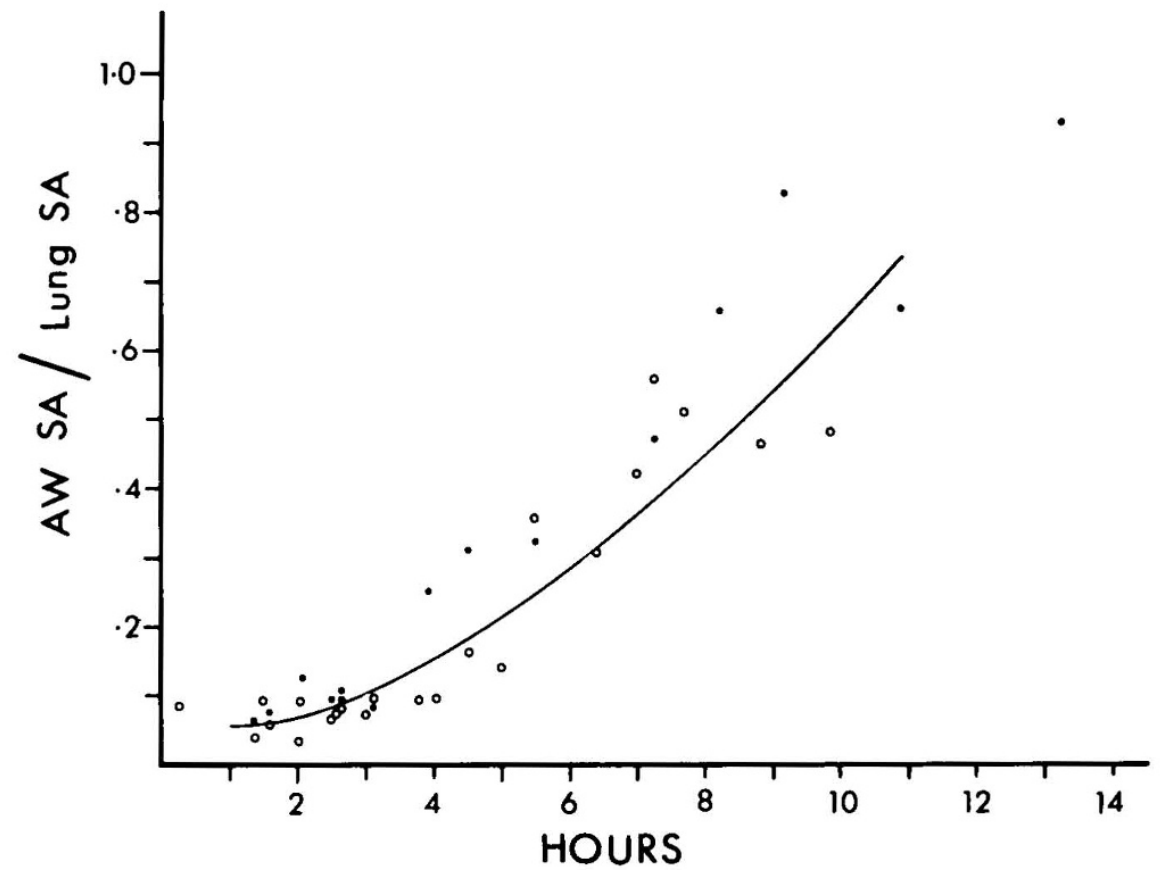

Fig. 5. Labeling of alveolar wash phosphatidylcholine in postmatures given $\left[{ }^{3} \mathrm{H}\right]$ palmitic acid $10 \mathrm{~min}$ before delivery. Three litters of 3-day postmature rabbits $(N=28)$ were delivered by caesarean section $10 \mathrm{~min}$ after the mother was given an injection of $2 \mathrm{mCi}\left[{ }^{3} \mathrm{H}\right]$ palmitic acid. The lung and alveolar wash lipid extracts were used to measure phosphatidyl- choline specific activities. A specific activity was expressed as the ratio of the specific activity of phosphatidylcholine or disaturated phosphatidylcholine in each alveolar wash fraction divided by its respective lung specific activity. $O$, phosphatidylcholine; $\bullet$, disaturated phosphatidylcholine.

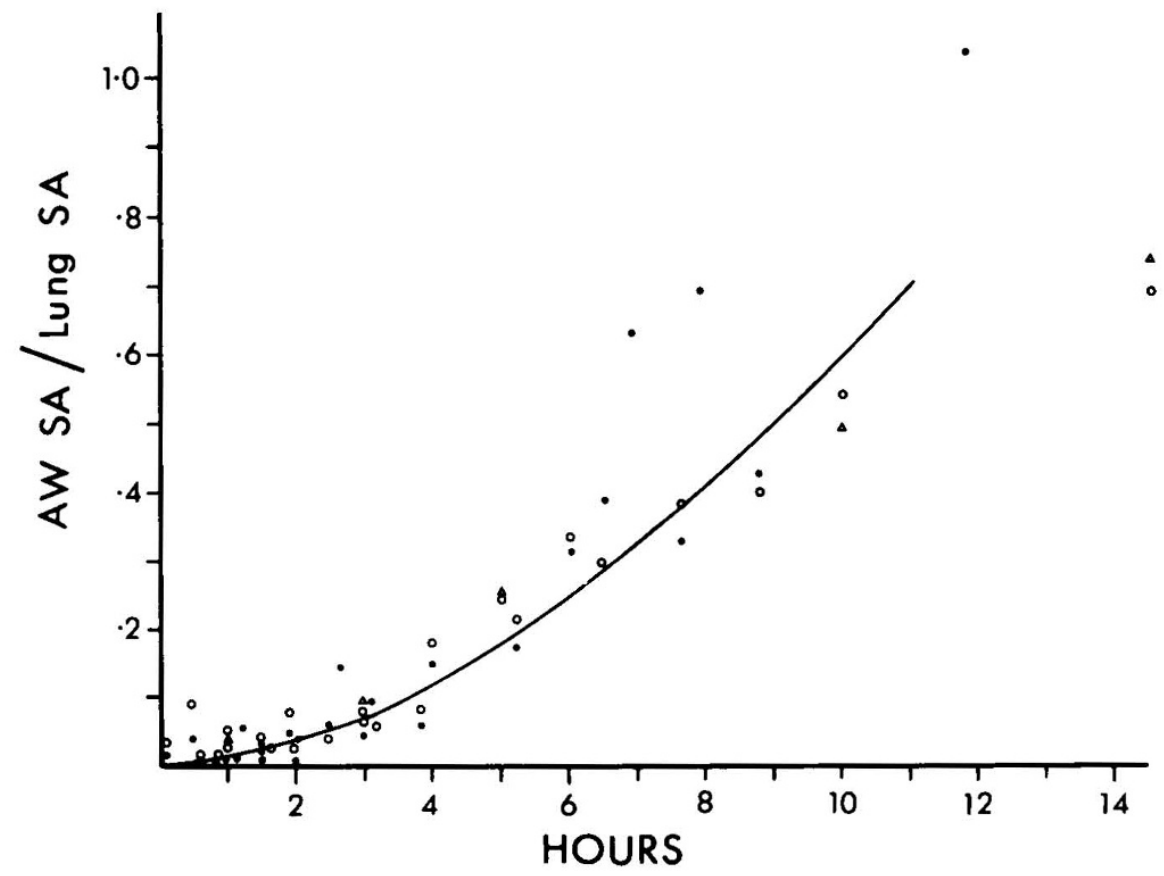

Fig. 6. Labeling of alveolar wash phosphatidylcholine in postmature rabbits. Postmature rabbits delivered approximately $1 \mathrm{hr}$ before injection were given $0.2 \mu \mathrm{Ci}\left[{ }^{14} \mathrm{C}\right]$ palmitic acid or $1 \mu \mathrm{Ci}\left[{ }^{3} \mathrm{H}\right]$ choline per $10 \mathrm{~g}$ body weight by IV injection. The specific activities of lung and alveolar wash phosphatidylcholine and disaturated phosphatidylcholine were measured and expressed as in Figure 5. $O$, phosphatidylcholine labeled with $\left[{ }^{14} \mathrm{C}\right]$ palmitic acid; 0 , disaturated phosphatidylcholine labeled with $\left[{ }^{14} \mathrm{C}\right] \mathrm{pal}$ mitic acid; $\Delta$, phospatidylcholine labeled with $\left[{ }^{3} \mathrm{H}\right]$ choline. similar (Figs. 5 and 6). As with the 3-day-old rabbits, the curves appear to be similar for phosphatidylcholine and disaturated phosphatidylcholine and independent of the radioactive precursor used. Again, little labeled phosphatidylcholine or disaturated phosphatidylcholine was detected in the alveolar wash fraction until 3 to $4 \mathrm{hr}$ after isotope injection. The accumulation of labeled phospholipids then was relatively linear; however, the time at which maximal specific activity of the phospholipids was achieved was not defined. The offset from the baseline for the specific activity ratios in Figure 5 probably resulted from the relatively low specific activities achieved when labeling of the fetal animals was attempted.

\section{DISCUSSION}

The labeling of alveolar wash disaturated phosphatidylcholine relative to the total alveolar wash phosphatidylcholine pool was 
compared in 3-day-old rabbits. The curves for the labeling of disaturated phosphatidylcholine with either $\left[{ }^{3} \mathrm{H}\right]$ glycerol or $\left[{ }^{14} \mathrm{C}\right]$ palmitic acid (Fig. 2) were the same as those for phosphatidylcholine labeled with $\left[{ }^{14} \mathrm{C}\right]$ palmitic acid (Figs. 1 and 3 ), $\left[{ }^{3} \mathrm{H}\right]$ choline (Fig. 1), or $\left[{ }^{3} \mathrm{H}\right]$ glycerol (Fig. 4). This implies that in 3-day-old rabbits the disaturated fraction of total alveolar wash phosphatidylcholine was processed from synthesis to secretion similarly to the total phosphatidylcholine pool. Furthermore, because curves generated using different precursors were indistinguishable, the kinetics of secretion were insensitive to the different incorporation pathways utilized by the different labeled precursors (31).

Have the curves measuring the accumulation of labeled alveolar wash phosphatidylcholine changed by 3 days of age from those measured in fetal (26), premature (23), and term newborn rabbits (24)? In term newborns, the delay of 3 to $4 \mathrm{hr}$ before labeled phosphatidylcholine was detected, and the long time required to reach maximal specific activity $(\sim 24 \mathrm{hr})$ contrast sharply with similar times in the adult (a delay of $\sim 1 / 2 \mathrm{hr}$, maximal specific activity by 6 to $8 \mathrm{hr})(21,25)$. All curves measured for the various phospholipids in the alveolar wash fractions from 3-day rabbits and 3-day postmature rabbits demonstrated the 3 to $4 \mathrm{hr}$ delay, indicating that the processing of alveolar wash phospholipids from synthesis to secretion was similar in all perinatal animals so far studied. A change toward the adult value must occur after 3 days of age. The maximal specific activities of phosphatidylcholine and disaturated phosphatidylcholine seemed to be achieved earlier ( 12 to $16 \mathrm{hr}$ ) in the 3 day old than in the younger animals (24). This change would be consistent with a "maturation" in the ability to effectively secrete the labeled phospholipids.

The presence of phosphatidylglycerol in amniotic fluid has been used to indicate lung maturity in the human fetus $(6,18)$. Similarly, phosphatidylglycerol in tracheal aspirates from premature infants will exclude the possibility of the respiratory distress syndrome developing (16). Whereas phosphatidylglycerol generally is detectable in the pulmonary or amniotic fluid of the human after 36 wk gestation age (18), phosphatidylglycerol normally is not present in the term rabbit, only to rapidly appear within the first several days of birth (17). The enzymes necessary for phosphatidylglycerol synthesis are present in preterm rabbit lung (35), and phosphatidylglycerol synthesis can be "induced" in vivo with dibutyryl cyclic adenosine $3^{\prime}: 5^{\prime}$-monophosphate (15). Because the kinetics of accumulation of labeled phosphatidylcholine in the alveolar wash fraction were very different in fetal, premature, and term newborn from adult rabbits, it was possible that the appearance of phosphatidylglycerol might correlate with a change from fetal adult patterns of phospholipid secretion. The 3-day-old rabbits with adult levels of phosphatidylglycerol in the alveolar wash fraction demonstrated secretion kinetics of labeled phosphatidylcholine or disaturated phosphatidylcholine similar to those of newborn rabbits (24). The kinetics of secretion of phosphatidylglycerol labeled either with $\left[{ }^{14} \mathrm{C}\right]$ palmitic acid or $\left[{ }^{3} \mathrm{H}\right]$ glycerol paralleled the curves for similarly labeled phosphatidylcholine. Whereas phosphatidylglycerol may be essential to surfactant function in the perinatal period (17), the in vivo labeling and secretion of phosphatidylglycerol were indistinguishable from that of phosphatidylcholine and disaturated phosphatidylcholine.

Phosphatidylinositol is a little-studied lung phospholipid found in low concentrations in surfactant. The only indication that phosphatidylinositol may be important to surfactant function is the developmental data showing a selective increase in the relative amount of phosphatidylinositol present in amniotic fluid samples and tracheal aspirates from human fetuses and newborns just before the expected appearance of phosphatidylglycerol in these biological fluids (16-18). Phosphatidylinositol increased from $3.9 \%$ of lung to $7.5 \%$ of alveolar wash fraction phospholipids in these 3-day-old rabbits, possibly indicating a preferential secretion of phosphatidylinositol, as the relative concentration of the phospholipid in alveolar wash was higher than the $5.2 \%$ measured in the adult rabbit (25). The role of phosphatidylinositol in surfactant phospholipid metabolism remains to be defined.

Phosphatidylethanolamine was the one phospholipid studied that was preferentially excluded from the alveolar wash; the percentage of composition in lung and alveolar wash was 18.0 and $4.7 \%$, respectively. Lung phosphatidylethanolamine is highly unsaturated (25), is not surface active (28), and is considered as a general membrane component. Phosphatidylethanolamine may have no function in surfactant, and may represent a "contaminant."

The 3-day postmature rabbits were studied at birth to see if the postterm pregnancy would influence lung maturation. However, because human chorionic gonadotropin was used to induce the postmaturity, the effects noted could be due to the hormone rather than to the prolonged pregnancy. This model of postmaturity was shown previously to perturb fetal lipid metabolism; there was a greater than $50 \%$ drop in fetal liver lipid concentration, and free fatty acids were less well transferred across the postterm placenta (37). Here, the striking finding was that $40 \%$ of the newborns had no detectable phosphatidylglycerol in lung, and $35 \%$ had no detectable phosphatidylglycerol in the alveolar wash fraction. The composition data were consistent with the idea that those animals stressed in utero were stimulated to make phosphatidylglycerol, whereas the unstressed animals experience a delay in maturation relative to the comparison group of 3-day-old rabbits. The curves for the labeling of the alveolar wash phosphatidylcholine and disaturated phosphatidylcholine in postmature rabbits either at or after delivery were similar to those for the 3-day-old rabbits.

\section{CONCLUSIONS}

By studying the kinetics of labeling of lung and alveolar wash phospholipids in 3-day and 3-day postmature rabbits, labeled disaturated phosphatidylcholine, phosphatidylcholine, phosphatidylglycerol, phosphatidylinositol, and phosphatidylethanolamine were shown to appear in the alveolar wash phospholipids with similar kinetics. Labeled phospholipids were not detected for 3 to $4 \mathrm{hr}$, and maximal specific activities were achieved in the alveolar wash by 12 to $16 \mathrm{hr}$. The labeling curves were similar for both the 3-day and 3-day postmature rabbits; however, many 3day postmature rabbit lung and alveolar wash fractions had either no detectable or low amounts of phosphatidylglycerol.

\section{REFERENCES AND NOTES}

1. Adams, F. H., Towers, B., Osher, A. B., Ikegami, M., Fujiwara, T., and Nozaki, $\mathbf{M}$ : Effects of tracheal instillation of natural surfactant in premature lambs: $I$. Clinical and autopsy findings. Pediatr. Res., 12: 841 (1978).

2. Avery, M. E., and Mead, J.: Surface properties in relation to atalectasis and hyalin membrane disease. Am. J. Dis. Child., 97: 517 (1959).

3. Bartlett, G. R.: Phosphorus assay in column chromatography. J. Biol. Chem., 234: 466 (1959).

4. Bligh, E. G., and Dyer, W. J.: A rapid method of total lipid extraction and purification. Can. J. Biochem. Physiol., 37: 911 (1959).

5. Brumley, G. W., Chernick, V., Hodson, W. A., Normand, C., Fenner, A., and Avery, M. E.: Correlations of mechanical stability, morphology, pulmonary surfactant and phospholipid content in the developing lamb lung. J. Clin. Invest., 46: 863 (1967)

6. Bustos, R., Kulovich, M. V., Gluck, L., Gabbe, S. G., Evertson, L., Vargas, C., and Lowerberg, E.: Significance of phosphatidylglycerol in amniotic fluid in complicated pregnancies. Am. J. Obstet Gynecol., 133: 899 (1979).

7. Chevalier, G., and Collet, A. J.: In vivo incorporation of choline- ${ }^{3} \mathbf{H}$, leucine- ${ }^{3} \mathbf{H}$, and galactose $-{ }^{3} \mathrm{H}$ in alveolar type II pneumocytes in relation to surfactant synthesis. Anat. Rec., 174: 289 (1972).

8. Darrah, H. K., and Hedley-Whyte, J.: Rapid incorporation of palmitate into lung: Site and metabolic fate. J. Appl. Physiol., 34: 205 (1973).

9. Gluck, L., and Kulovich, M. V.: Lecithin/sphingomyelin ratios in amniotic fluid in normal and abnormal pregnancy. Am. J. Obstet. Gynecol., 115: 539 (1973).

10. Gluck, L., Kulovich, M. V., Borer, R. C., Brenner, P., Anderson, G. G., and Spellacy, W. N.: Diagnosis of the respiratory distress syndrome by amniocentesis. Am. J. Obstet. Gynecol., 109: 440 (1971).

11. Gluck, L., Motoyama, E. K., Smits, H. L., and Kulovich, M. V.: The biochemical development of surface activity in mammalian lung. Pediatr. Res., I: 237 (1967).

12. Gluck, L., Sribney, M., and Kulovich, M. V.: The biochemical development of surface activity in mammalian lung. Pediat. Res., 1: 247 (1967).

13. Gregory, G. A., Kitterman, J. A., Phibbs, R. H., Tooley, W. H., and Hamilton, W. K.: Treatment of the idiopathic respiratory distress syndrome with continuous positive airway pressure. N. Engl. J. Med., 284: 1333 (1971).

14. Gross, I., Wilson, C. M., and Rooney, S. A.: Phosphatidylcholine synthesis in newborn rabbit lung: developmental pattern and the influence of nutrition. Biochim. Biophys. Acta, 528: 190 (1978). 
15. Hallman, $M$.: Induction of surfactant phosphatidylglycerol in the lung of fetal and newborn rabbits by dibutyryl adenosine $3^{\prime}: 5^{\prime}$-monophosphate. Biochem. Biophys. Res. Commun., 77: 1094 (1977).

16. Hallman, M., Feldman, B. H., Kirkpatrick, E., and Gluck, L.: Absence of phosphatidylglycerol (PG) in respiratory distress syndrome in the newborn: study of the minor surfactant phospholipids in newborns. Pediatr. Res., 11: 714 (1977).

17. Hallman, M., and Gluck, L.: Phosphatidylglycerol in lung surfactant; III. Possible modifier of surfactant function. J. Lipid Res., 17: 257 (1976).

18. Hallman, M., Kulovich, M. V., Kirkpatrick, E., Sugarman, R. G., and Gluck, L.: Phosphatidylinositol and phosphatidylglycerol in amniotic fluid: indices of lung maturity. Am. J. Obstet. Gynecol., 125: 613 (1976).

19. Ikegami, M., Hesterberg, T., Nozaki, M., and Adams, F. H.: Restoration of lung pressure-volume characteristics with surfactant: comparison of nebulization versus instillation and natural versus synthetic surfactant. Pediatr. Res., 1I: 178 (1977).

20. Jacobs, K. W.: A table for the determination of experimentwise error rate for independent comparisons. Educ. Physiol. Measurements, 36: 899 (1976).

21. Jobe, A.: The labeling and biological half-life of phosphatidylcholine in subcellular fractions of rabbit lung. Biochim. Biophys. Acta, 489: 440 (1977).

22. Jobe, A.: An in vivo comparison of acetate and palmitate as precursors of surfactant phosphatidylcholine. Biochim. Biophys. Acta, 572: 404 (1979).

23. Jobe, A., and Gluck, L.: The labeling of lung phosphatidylcholine in premature rabbits. Pediatr. Res., 13: 635 (1979).

24. Jobe, A., Kirkpatrick, E., and Gluck, L.: Lecithin appearance and apparent biological half-life in term newborn rabbit lung. Pediatr. Res., 12: 669 (1978).

25. Jobe, A., Kirkpatrick, E., and Gluck, L.: Labeling of phospholipid in the surfactant and subcellular fractions of rabbit lung. J. Biol. Chem., 253: 3810 (1978).

26. Jobe, A., Mannino, F., and Gluck, L.: The labeling of phosphatidycholine in the alveolar wash of rabbits in utero. Am. J. Obstet. Gynecol., 132: 53 (1978).

27. Liggins, G. C., and Howie, R. N.: A controlled trial of antepartum glucocorticoid treatment for the prevention of the respiratory distress syndrome in premature infants. Pediatrics, 50: 115 (1972).

Copyright $(\subset) 1980$ International Pediatric Research Foundation, Inc. 0031-3998/80/1404-0319\$02.00/0
28. Lusted, D.: Rheologic hysteresis curve shape specificity of mixed lipid films. Biochim. Biophys. Acta, 307: 270 (1973).

29. Mason, R. J., Nellenbogen, J., and Clements, J. A.: Isolation of disaturated phosphatidylcholine with osmium tetroxide. J. Lipid Res., 17: 281 (1976).

30. Nilsson, R., Grossman, G., and Robertson, B.: Lung surfactant and pathogenesis of neonatal bronchiolar lesions induced by artificial ventilation. Pediatr. Res., 12: 249 (1978).

31. Ohno, K., Akino, T., and Fujiwara, T.: Phospholipid metabolism in perinatal lung, In: E. M. Scarpelli, E. V. Cosmi: Reviews in Perinatal Medicine. Vol. 2. p. 227 (Raven Press, New York, 1978).

32. Oryalesi, M. M., Motoyama, E. K., Jacobson, H. N., Kikkawa, Y., Reynolds, E. O. R., and Cook, C. D.: The development of the lungs of lambs. Pediatrics, 35: 343 (1965).

33. Platzker, A. C. G., Kitterman, J. A., Mescher, E. J., Clements, J. A., and Tooley, W. H.: Surfactant in the lung and tracheal fluid of the fetal lamb and acceleration of its appearance by dexamethasone. Pediatrics, 56: 554 (1975).

34. Reynolds, E. O. R., and Taghizadeh, A.: Improved prognosis of infants mechanically ventilated for hyalin membrane disease. Arch. Dis. Child., 49: 505 (1974).

35. Rooney, S. A., Gross, I., Grassenheimer, L. N., and Motayama, E. K.: Stimulation of glycerophosphate phosphatidyltransferase activity in fetal rabbit lung by cortisol administration. Biochim. Biophys. Acta, 398: 433 (1975).

36. Scarpelli, E. M.: The lung, tracheal fluid, and lipid metabolism of the fetus. Pediatrics, 40: 951 (1967).

37. Shapiro, M. I., and Roux, J. F.: Lipid transport and metabolism in the postterm rabbit. Am. J. Obstet. Gynecol., 129: 171 (1977).

38. I thank Phyllis Yip for excellent technical assistance.

39. Requests for reprints should be addressed to: Alan Jobe, M.D., Fetal-Maternal Research Laboratories, Los Angeles County Harbor-UCLA Medical Centre. 1000 W. Carson, Bldg. A-17, Torrance, CA 90509 (USA).

40. This research was supported By NIH Grant HD-11932 and by Research Career Development Award HD-HL-00252.

41. Received for publication November 21, 1978.

42. Accepted for publication June 1, 1979.

Printed in U.S.A. 